\title{
Correction \\ Correction: Wang, C.; et al. Postgraduate Education of Board Members and R\&D Investment-Evidence from China. Sustainability 2019, 11, 6524
}

\author{
Chuanyi Wang ${ }^{1}\left(\mathbb{D}\right.$, Jiale Yang $\left.{ }^{1, *} \mathbb{(}\right)$, Zhe Cheng ${ }^{1}$ and Chaoqun $\mathrm{Ni}^{2, *}$ \\ 1 Institute of Education, Tsinghua University, Beijing 100084, China; wcy1985@tsinghua.edu.cn (C.W.); \\ chengz19@mails.tsinghua.edu.cn (Z.C.) \\ 2 School of Library and Information Science, University of Iowa, Iowa City, IA 52242, USA \\ * Correspondence: yj118@mails.tsinghua.edu.cn (J.Y.); chaoqun.ni@wisc.edu (C.N.)
}

check for updates

Citation: Wang, C.; Yang, J.; Cheng, Z.; Ni, C. Correction: Wang, C.; et al. Postgraduate Education of Board Members and R\&D Investment-Evidence from China. Sustainability 2019, 11, 6524

Sustainability 2021, 13, 3324.

https://doi.org/10.3390/su13063324

Received: 10 March 2021

Accepted: 14 March 2021

Published: 17 March 2021

Publisher's Note: MDPI stays neutral with regard to jurisdictional claims in published maps and institutional affiliations.

Copyright: (c) 2021 by the authors. Licensee MDPI, Basel, Switzerland. This article is an open access article distributed under the terms and conditions of the Creative Commons Attribution (CC BY) license (https:/ / creativecommons.org/licenses/by/ $4.0 /)$.
The authors would like to make the following corrections to the published paper [1]. The changes are as follows:

(1) Replacing the email address of the fourth author:

chaoqun-ni@uiowa.edu with

chaoqun.ni@wisc.edu;

(2) Replacing the sentence in Section 4.4., "Robustness Test", on page 12:

"The second stage regression shows the coefficient of a directors' master's degree is still significantly negative." with

"The second stage regression results are consistent with Table 5.";

(3) Replacing the sentence in Section 4.4., "Robustness Test", on page 12:

"F statistics $(\mathrm{F}=25.82)$ is greater than the normal threshold of 10 , indicating our IV passes the weak IV test and has strong explanatory power to the endogenous variable." with

"F statistics $(\mathrm{F}=24.80)$ is greater than the normal threshold of 10 , indicating our IV passes the weak IV test and has strong explanatory power to the endogenous variable.";

(4) Deleting "in the IT industry" in the sentence of "Therefore, we used engagement in R\&D work as the IV to test the robustness of our research results in the IT industry." in Section 4.4., "Robustness Test", on page 12;

(5) Deleting "in the IT industry" from the Table 9 caption: "IV 2SLS regression results in the IT industry" on page 12.

(6) Authors would like to update the data in Table 9, so we need to replace the original Table 9:

Table 9. IV 2SLS regression results in the IT industry.

\begin{tabular}{cccc}
\hline & First Stage & Second Stage & OLS \\
\hline IFRD & $0.62^{* * *}$ & & \\
& $(5.08)$ & 1.49 & 0.33 \\
PDD & & $(0.51)$ & $(0.25)$ \\
& & $-3.94^{* *}$ & $-3.91 * *$ \\
PMD & -0.13 & $(-2.11)$ & $(-2.38)$ \\
& $(-1.42)$ & -1.27 & -1.02 \\
PEM & $0.26^{* *}$ & $(-0.49)$ & $(-0.46)$ \\
& $(2.08)$ & & \\
\hline
\end{tabular}


Table 9. Cont.

\begin{tabular}{cccc}
\hline & First Stage & Second Stage & OLS \\
\hline PSE & 0.31 & -0.24 & -0.01 \\
& $(1.59)$ & $(-0.09)$ & $(-0.00)$ \\
PC9 & -0.02 & 2.91 & 2.98 \\
& $(-0.11)$ & $(1.08)$ & $(1.19)$ \\
POI & 0.15 & 1.00 & 1.26 \\
& $(0.77)$ & $(0.41)$ & $(0.40)$ \\
ALR & -0.18 & $-13.43^{* * *}$ & $-13.83^{* * *}$ \\
& $(-0.86)$ & $(-3.08)$ & $(-3.65)$ \\
RDE & $-0.83^{* * *}$ & 0.58 & $(0.23)$ \\
& $(-4.64)$ & $(0.26)$ & $17.55^{* * *}$ \\
Constant & $0.33^{* * *}$ & $17.05^{* * *}$ & $(8.25)$ \\
& $(2.80)$ & $(4.55)$ & 148 \\
N & 148 & 148 & \\
Partial R & 0.14 & & \\
F & 25.82 & &
\end{tabular}

Note: $t$ statistics in parentheses. ${ }^{*} p<0.1,{ }^{* *} p<0.05,{ }^{* * *} p<0.01$.

with

Table 9. IV 2SLS regression results.

\begin{tabular}{ccc}
\hline & First Stage & Second Stage \\
\hline IFRD & $0.27^{* * *}$ & \\
PDD & $(0.03)$ & $2.44^{* *}$ \\
PMD & & $(2.30)$ \\
& & 0.23 \\
PEM & -0.11 & $(0.88)$ \\
& $(-0.03)$ & -0.52 \\
PSE & $0.27^{* * *}$ & $(-1.16)$ \\
& $(0.04)$ & 0.15 \\
PC9 & $0.43^{* * *}$ & $(0.20)$ \\
& $(0.05)$ & 0.05 \\
POI & -0.01 & $(0.11)$ \\
& $(0.05)$ & -0.30 \\
ALR & 0.07 & $(-0.68)$ \\
& $(0.05)$ & $-5.33^{* * *}$ \\
Industry & 0.21 & $(-4.84)$ \\
Constant & $(0.07)$ & $2.78^{* * *}$ \\
& & $(4.11)$ \\
\hline $\mathrm{N}$ & 0.09 & 1374 \\
$\mathrm{r}^{2}$ & $(0.10)$ & 0.17 \\
$\mathrm{~F}$ & 1374 & \\
\hline
\end{tabular}

Note: $t$ statistics in parentheses. ${ }^{*} p<0.1,{ }^{* *} p<0.05,{ }^{* * *} p<0.01$.

\section{Reference}

1. Wang, C.; Yang, J.; Cheng, Z.; Ni, C. Postgraduate Education of Board Members and R\&D Investment-Evidence from China. Sustainability 2019, 11, 6524. [CrossRef] 